\title{
Analisis Aspek-Aspek Kualitas Skema Database Kepegawaian untuk Optimalisasi Perekrutan Karyawan
}

\author{
Analysis of Quality Aspects of Employee Database Scheme \\ to Optimize Employee Recruitment
}

\author{
Vera Wati*1, Akrilvalerat D W' ${ }^{2}$, Nur Fitrianingsih Hasan ${ }^{3}$, Irfan Purwanto ${ }^{4}$, \\ Joni Saputra $^{5}$, Lukmanul Hakim ${ }^{6}$, M. Afriansyah ${ }^{7}$ \\ 1,2,3,4,5,6,7 Magister Teknik Informatika Universitas AMIKOM Yogyakarta, \\ E-mail:*1verave.wati@gmail.com, 2 akrilvha8@gmail.com, \\ ${ }^{3}$ fitriahasan.papuan@gmail.com, ${ }^{4}$ irfanpurwanto96@gmail.com, \\ ${ }^{5}$ saputrajoni798@gmail.com, ${ }^{6}$ lukmanulhkim@gmail.com, ${ }^{7}$ afriansyah40@gmail.com
}

\begin{abstract}
Abstrak
Permasalahan manajemen kepegawaian pada Kantor Kementerian khususnya kantor Pekerjaan Umum adalah pada data kepegawaian, data pegawai yang di setiap tahunnya mengalami pengurangan dan penambahan, sehingga perlunya analisis data pegawai untuk mengetahui kebutuhan pegawai (SDM) tersebut sesuai dengan jabatan dan kebutuhan. Solusi dari permasalahan diatas yaitu menganalisa database yang lama dan merekomendasikan skema database yang baru dengan menganalisis dari aspek-aspek kualitas skema database untuk memberikan rekomendasi langkah yang sesuai kebutuhan kepegawaian khususnya pada data pegawai yang berhubungan dengan data pensiun dan data jabatan minimal 3 tahun yang sudah ada, agar tidak adanya tumpang tindih pegawai dalam satu unit dan agar mempermudah dalam mendata kebutuhan SDM untuk keperluan rekrutmen karyawan yang lebih seimbang, terstruktur, efektif dan efisien. Hasil dari menganalisa database kepegawaian ini menggunakan acuan dari aspek-aspek kualitas skema database yang meliputi kebenaran dengan belum ada kejelasan pada kepemilikan constraint, konsistensi penghapusan pada primary key yang berpengaruh ke foreign key dan relevansi masih diperlukan reference primary key ada parent table ke child table.
\end{abstract}

Kata Kunci — kualitas, skema database, kepegawaian, optimalisasi

\begin{abstract}
Personnel management problems in the Office of the Ministry especially the Public Works office are on staffing data, the data of employees in each year experience a reduction and addition, so the need for employee data analysis to determine the needs of employees (HR) in accordance with their position and needs. The solution to the above problems is analyzing the old database and recommending a new database scheme by analyzing the quality aspects of the database schema to provide recommendations for steps that suit staffing requirements, especially on employee data relating to pension data and minimum 3-year occupational data that already exists In order to avoid overlapping employees in one unit and to make it easier to record HR needs for more balanced, structured, effective and efficient employee recruitment needs. The results of analyzing this personnel database use references from database aspects that contain truth with no clarity on constraint ownership, consistency in primary keys related to foreign keys and relevance still requires primary key references there are parent tables to child tables.
\end{abstract}

Keywords — quality, scheme database, employee, optimization 


\section{PENDAHULUAN}

Perkembangan teknologi informasi kini semakin berkembang, dimana semakin banyak pemanfaatannya di semua bidang kehidupan. Informasi kini sudah terkomputerisasi dan memiliki ukuran semakin kecil dan kecepatan akses yang semakin mempersingkat waktu. Penggunaan teknologi informasi yang tepat dapat membantu dalam mengambil keputusan dimana penyimpanan data telah didukung oleh salah satu komponen penting dari teknologi informasi yaitu database. Pemanfaatan database memungkinkan untuk dapat menyimpan data atau melakukan perubahan dan menampilkan kembali data tersebut dengan cepat dan mudah [1].

Pada analisis data kepegawaian di kantor kementerian terdapat beberapa tabel yang belum disesuaikan dengan kebutuhan. Masih terdapat beberapa data yang tingkat akurasinya kurang, terjadinya redudansi data serta penggunaan beban memori untuk penyimpanan yang harus nya disesuaikan dengan kebutuhan. Permasalahan manajemen kepegawaian pada Kantor Kementerian khususnya kantor Pekerjaan Umum adalah pada data kepegawaian, data pegawai yang di setiap tahunnya mengalami pengurangan dan penambahan, sehingga perlunya analisis data pegawai untuk mengetahui kebutuhan pegawai (SDM) tersebut.

Mengacu pada penelitian terdahulu oleh Ema Utami, dkk yang menganalisis aspek-aspek kualitas schema database dimana telah melakukan penelitian terhadap 6 aspek kualitas database yang meliputi aspek Kebenaran, Konsistensi, Relevansi, Jangkauan, Tingkat Detail, Kelengkapan, Minimalis dan Kemampuan untuk diintegrasikan pada akademik ISTA telah menghasilkan berupa kesimpulan analisa yang dilakukan pada rancangan skema database akademik yang digunakan ISTA berdasarkan aspek-aspek kualitas sesuai dengan penelitiannya [2]. Namun pada penelitian ini akan di fokuskan pada aspek kualitas Kebenaran, Konsistensi dan Relevansi yang di bahas secara mendalam dengan pembuktian query yang disertakan.

Penelitian ini akan melakukan analisis atau pengujian mengenai aspek-aspek kualitas skema database, seperti halnya dalam pengaturan data yang lengkap secara efektif dan sebagai keperluan analisis dalam mengolah sejumlah data, sesuai dengan jangkauan kebutuhan data, kebenaran konsistensi dan relevan dalam pengelolaan data, hingga kecepatan dalam memperoleh informasi yang relevan. Hal ini dilakukan agar mendapatkan gambaran tabel rekomendasi baru yang terintegrasi dan saling terelasi secara logis yang dirancang untuk memenuhi kebutuhan informasi dari kepentingan pada urusan kantor kementerian.

Pada penelitian ini hanya akan terkonsentrasi menganalisa 3 aspek yaitu meliputi kebenaran (correctness), konsistensi (consistency), dan relevansi (relevance), karena ketiga aspek tersebut saling berelasi. Dimana dalam aspek kebenaran akan menekankan pada ketidakakuratan dalam penyimpanan data dan pemilihan tipe data sesuai kondisi, namun hal tersebut harus memperhatikan mengenai kekonsistensian pada skema database. Kriteria konsistensi mengacu pada model skema data agar terbebas dari kontradiksi sehingga skema database tersebut memiliki aspek-aspek yang relevan digunakan. Sehingga hasil yang diharapkan dalam penelitian ini adalah menghasilkan skema data dengan aspek-aspek tersebut yang ditekankan pada penggunaan tipe data yang sesuai tanpa redudansi.

Proses menganalisa aspek-aspek skema pada database kepegawaian tersebut, peneliti menggunakan query INSERT pada aspek kebenaran (correctness), sebagai pengukuran kualitas dan pembuktian jika dalam menambahkan data yang baru atau sama apakah mengandung nilai keakuratan informasi atau sebaliknya. Sedangkan dalam proses analisa query aspek konsistensi (consistency) menggunakan perintah JOIN dari beberapa tabel untuk memperoleh informasi pengeksekusian tanpa redudansi data. Aspek relevansi (relevance) dengan penggunaan query DELETE, yang dilakukan penghapusan table pada parent table dan membuktikan jika child table terjadi penghapusan atau sebaliknya. Sehingga pada pengujian dengan query pada aspek relevansi sudah membuktikan jika hubungan antara parent table dengan child table memang sudah terelevansi hubungan tiap tabelnya.

Berdasarkan latar belakang yang ada, penelitian ini diharapkan mampu menghasilkan informasi hubungan antar tabel dalam skema database yang sudah memenuhi aspek kebenaran, konsistensi dan relevan dengan pemilihan query yang sudah disesuaikan oleh peneliti dalam 
pengujian. Sehingga informasi yang didapatkan guna untuk mengetahui data pada kepegawaian menggunakan beban memori sesuai penyimpanan yang sesuai kebutuhan. Hal ini tentu menjadi informasi yang menjadikan pengurangan dan penambahan pegawai tiap tahunnya sesuai data yang benar, konsisten dan relevan.

Perancangan database relasional diperlukan untuk mendapatkan sekumpulan skema relasi yang baik. Rancangan yang buruk akan mengakibatkan perulangan informasi maupun informasi yang tidak sesuai. Tujuan dari perancangan database sendiri adalah untuk menghindari kerangkapan data, menjamin kerelasian antar atribut dan fasilitas pengecekan batasan integritas pada proses update. Menurut J. L. Whitten dan L. D. Bentley, tujuan dan prasyarat perancangan database adalah [3]:

1. Database harus memberikan efisiensi media penyimpan (storage), update, dan penampilan kembali data-data.

2. Database harus andal, yaitu memiliki integritas tinggi yang memberikan kepercayaan bagi para pengguna terhadap data.

3. Database harus dapat beradaptasi (adaptable) dan dapat berkembang (scalable) untuk memenuhi kebutuhan dan aplikassi baru.

\section{METODE PENELITIAN}

Metodologi adalah satuan metode-metode, prosedur-prosedur, konsep-konsep pekerjaan, aturan-aturan dan postulat-postulat yang digunakan oleh suatu ilmu pengetahuan, seni atau disiplin lainnya. Sedangkan metode adalah suatu cara/penelitian pendekatan kualitatif [4].

Pada metode penelitian akan dijelaskan mengenai langkah-langkah dalam menyelesaikan permasalahan yang dibahas, agar mendapatkan hasil yang optimal. Penggambaran metode ini di ilustrasikan dengan menggunakan rancangan logika menggunakan Diagram Alir Data (DAD) [5]. Hal ini menunjukan kinerja yang menjelaskan jika ada input data oleh user atau pengguna dalam sistem database kepegawaian. Pada sistem database kepegawaian ini akan menampung berbagai data yang berkaitan dengan database kepegawaian data PNS pada Kementerian XYZ. Sistem Rancangan penelitian dalam DAD dapat dilihat pada Gambar 1.

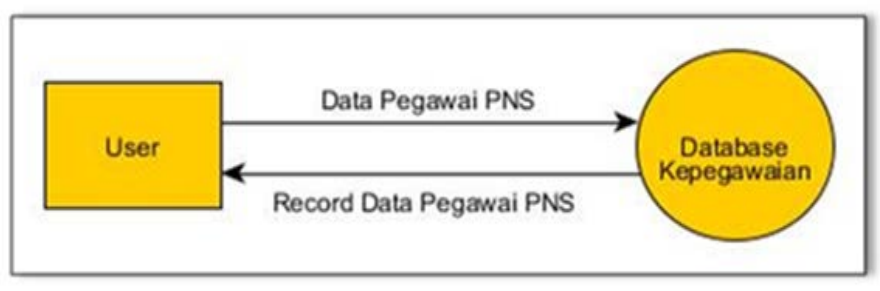

Gambar 1. Diagram Alir Data Database Kepegawaian

Penjelasan dari Gambar 1 adalah menjelaskan proses kerja dari pengelolaan database kepegawaian PNS pada yang mendapat input data kepegawaian dalam mengubah satu arah antara user dengan sistem database. Saat user memasukkan berupa data lengkap pegawai PNS maka akan diproses dan terjadi disimpan di dalam sistem database kepegawaian, sehingga output kepada user adalah berupa record data pegawai PNS.

Dalam penyusunan input data kepegawaian pada sistem database dilakukan dengan menggunakan pendekatan model database. Pendekatan model database menurut Raymond dan George Schell (2001) menyatakan menggunakan dua pendekatan, yaitu Pendekatan berorientasi proses (pendekatan pemecahan masalah) [6]. Pendekatan, model perusahaan. Selanjutnya, penyusunan dengan tiga langkah antara lain:

1. Mendeskripsikan data

Pada proses mendeskripsikan data adalah dimana proses ini menggambarkan data yang ada berdasarkan data mentah kepegawaian di kementerian XYZ yang mana data mentah tersebut 
berupa data pada file excel. Cara penyusunan lain dengan penyusunan pengelompokan data, sehingga memberikan gambaran nyata guna diproses selanjutnya.

2. Memasukkan data

Setelah beberapa data tersebut dideskripsikan dan dikelompokan sesuai dengan kebutuhan dan batasan sistem maka harus disimpan sesuai dengan field-field yang akan dibuat dalam skema database.

3. Menggunakan database (menggunakan bahasa query, QBE, DML)

Penelusuran dengan menggunakan query dilakukan guna mendapatkan temuan-temuan terhadap faktor-faktor skema database yang dapat dilakukan optimasi. Penelusuran yang dilakukan adalah dengan menggunakan query INPUT, DELETE, UPDATE, SELECT dan JOIN terhadap tabel-tabel yang berelasi [7].

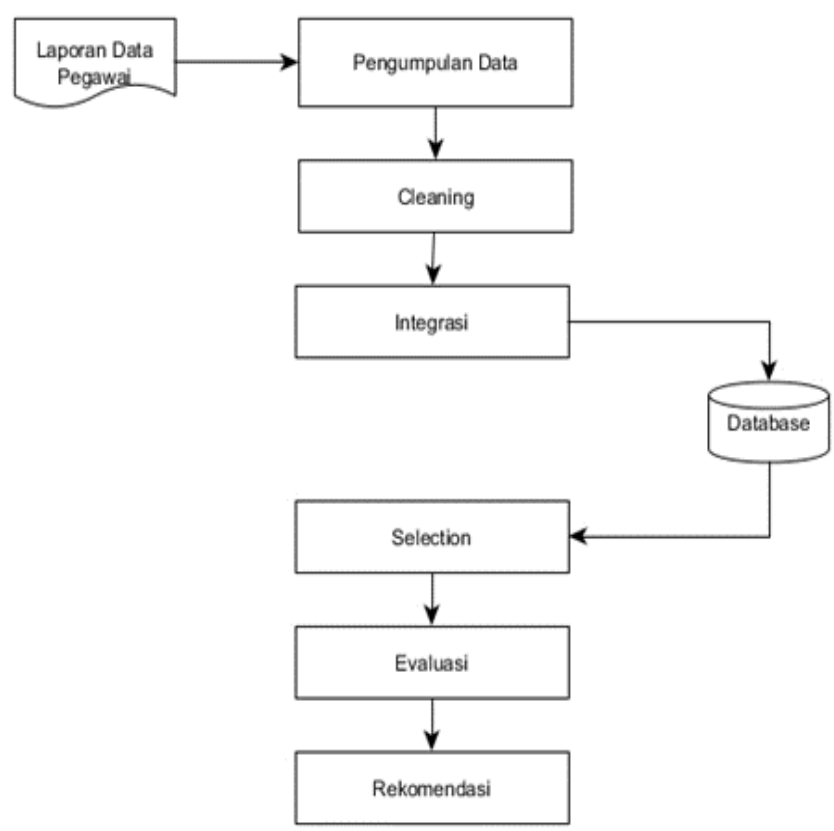

Gambar 2. Prosedur Penyusunan Rancangan Database

Pada proses perancangan skema database dibuat dari alur pengumpulan data dari Microsoft Excel yang selanjutnya diproses cleaning data yang kosong atau data mengandung noise dan tidak sesuai. Sumber yang berasal dari laporan data kepegawaian dilakukan proses pengumpulan pada Microsoft Excel untuk kemudian dilakukan cleaning yaitu pembersihan data yang mengandung data tidak sesuai ketentuan seperti data pegawai yang non-pns, pegawai yang sudah pensiun. Setelah itu, proses migrasi pada database sesuai kebutuhan tabel-tabel yang akan digunakan yaitu pada proses selection. Pada tahap tersebut terjadi proses pemilihan tabel yang akan dianalisa yaitu tabel yang berelasi dengan tabel pegawai, seperti tabel bagian, tabel jabatan, tabel agama, tabel jenjang pendidikan, dan lainnya. Setelah tabel saling berelasi kemudian tabel di evaluasi sesuai aspek-aspek database yaitu kebenaran, konsisten dan relevan. Tahap terakhir adalah rekomendasi, berdasarkan hasil-hasil yang diperoleh. Prosedur penyusunan sehingga terjadinya rancangan database bisa dilihat pada Gambar 2.

\section{HASIL DAN PEMBAHASAN}

Pendeskripsian data yang dilakukan dari data mentah berupa data excel, yang mana berisi data pada tahun 2016-2018 dengan jumlah record data identitas pegawai 686 pada tahun 2016, 677 pada tahun 2017 dan 851 pada tahun 2018. Sampel data mentah yang diperoleh bisa dilihat pada tabel 1 yang merupakan data pada tahun 2016. 
Tabel 1. Daftar Susunan Pegawai Negeri Sipil dan Non Sipil

Kantor Kepegawaian Umum Tahun Anggaran 2016

\begin{tabular}{|c|c|c|c|c|c|c|c|}
\hline \multirow{2}{*}{ No } & \multirow{2}{*}{ Nama } & \multirow{2}{*}{ NIP } & \multirow{2}{*}{ Pangkat/Gol } & \multicolumn{2}{|c|}{ Jabatan } & \multirow{2}{*}{ Pend. } & \multirow{2}{*}{ Ket. } \\
\hline & & & & Lama & Baru & & \\
\hline A. & \multicolumn{7}{|l|}{ Struktural Balai } \\
\hline 1. & $\begin{array}{l}\text { Ir. Abdul Latif, } \\
\text { M.A }\end{array}$ & $\begin{array}{l}1872021 \\
1929291002\end{array}$ & $\begin{array}{l}\text { Pembina } \\
\text { Utama Muda } \\
\text { IV/a }\end{array}$ & Kepala Balai Besar & Kepala Balai Besar & S2 & \\
\hline 2. & Ir. Suharto, M.T & $\begin{array}{l}18670929 \\
1989111001\end{array}$ & $\begin{array}{l}\text { Pembina Tk. I } \\
\text { IV/a }\end{array}$ & $\begin{array}{l}\text { Teknik Pengairan } \\
\text { Madya }\end{array}$ & $\begin{array}{l}\text { Teknik Pengairan } \\
\text { Madya }\end{array}$ & S2 & \\
\hline 3. & $\begin{array}{l}\text { Ir. Ahmad } \\
\text { Jaelani }\end{array}$ & $\begin{array}{l}19878288 \\
1987821001\end{array}$ & Pembina IV/a & $\begin{array}{l}\text { Teknik Pengairan } \\
\text { Madya }\end{array}$ & $\begin{array}{l}\text { Teknik Pengairan } \\
\text { Madya }\end{array}$ & S2 & \\
\hline 4. & $\begin{array}{l}\text { Siswati, S.T, } \\
\text { M.T }\end{array}$ & $\begin{array}{l}1959901 \\
19890211003\end{array}$ & Pembina IV/a & $\begin{array}{l}\text { Teknik Pengairan } \\
\text { Madya }\end{array}$ & $\begin{array}{l}\text { Teknik Pengairan } \\
\text { Madya }\end{array}$ & S2 & \\
\hline 5. & Sri Lestari & $\begin{array}{l}1986047 \\
2008122001\end{array}$ & Pengatur II/d & $\begin{array}{l}\text { Pengadministrasi } \\
\text { Umum }\end{array}$ & $\begin{array}{l}\text { Pengadministrasi } \\
\text { Umum }\end{array}$ & SMA & \\
\hline \multicolumn{8}{|c|}{ Non PNS } \\
\hline 6. & Rusminiyati & - & II/a & $\begin{array}{l}\text { Pengadministrasi } \\
\text { Umum }\end{array}$ & $\begin{array}{l}\text { Pengadministrasi } \\
\text { Umum }\end{array}$ & SLTA & \\
\hline B. & \multicolumn{7}{|c|}{ Bagian Tata Usaha } \\
\hline 7. & $\begin{array}{l}\text { Ir. Edi Suryadi, } \\
\text { M.Eng }\end{array}$ & \begin{tabular}{|l|}
19741124 \\
1990012001 \\
\end{tabular} & $\begin{array}{l}\text { Pembina Tk. I } \\
\text { IV/b }\end{array}$ & $\begin{array}{l}\text { Kepala Bagian } \\
\text { Tata Usaha } \\
\end{array}$ & $\begin{array}{l}\text { Kepala Bagian } \\
\text { Tata Usaha } \\
\end{array}$ & S2 & \\
\hline 8. & $\begin{array}{l}\text { Agung Prasetso, } \\
\text { S.T }\end{array}$ & \begin{tabular}{|l|}
19670512 \\
2000121004 \\
\end{tabular} & $\begin{array}{l}\text { Penata Tk. I } \\
\text { III/d }\end{array}$ & Arsiparis Muda & Arsiparis Muda & S1 & rangkap \\
\hline 9. & Angelica, M.SE & \begin{tabular}{|l|l}
19891208 \\
2005011015 \\
\end{tabular} & Penata III/c & $\begin{array}{l}\text { Analis } \\
\text { Kepegawaian Muda }\end{array}$ & $\begin{array}{l}\text { Analis } \\
\text { Kepegawaian Muda }\end{array}$ & S1 & \\
\hline & Non PNS & & & & & & \\
\hline 10 & $\begin{array}{l}\text { Hapsari Dewi } \\
\text { Aryani }\end{array}$ & - & $\mathrm{II} / \mathrm{a}$ & $\begin{array}{l}\text { Pengadministrasi } \\
\text { Umum }\end{array}$ & $\begin{array}{l}\text { Pengadministrasi } \\
\text { Umum }\end{array}$ & SMA & \\
\hline
\end{tabular}

Dari data mentah ini dilakukan pengolahan dengan menelusuri data, menyeleksi data (memilih data PNS dan menyeleksi data Non-CPNS dan meyeleksi data pegawai yang sudah pensiun), membuat RDBMS dan terakhir menganalisa aspek-aspek kualitas database yakni Kebenaran, Konsistensi dan Relevansi. Database baru dirancang menggunakan MYSQL karena aplikasi tersebut merupakan aplikasi database yang mendukung fitur check constraint. Check constraint sendiri digunakan untuk membatasi penambahan data pada database [8]. Skema database data kepegawaian ditunjukkan pada Gambar 3.

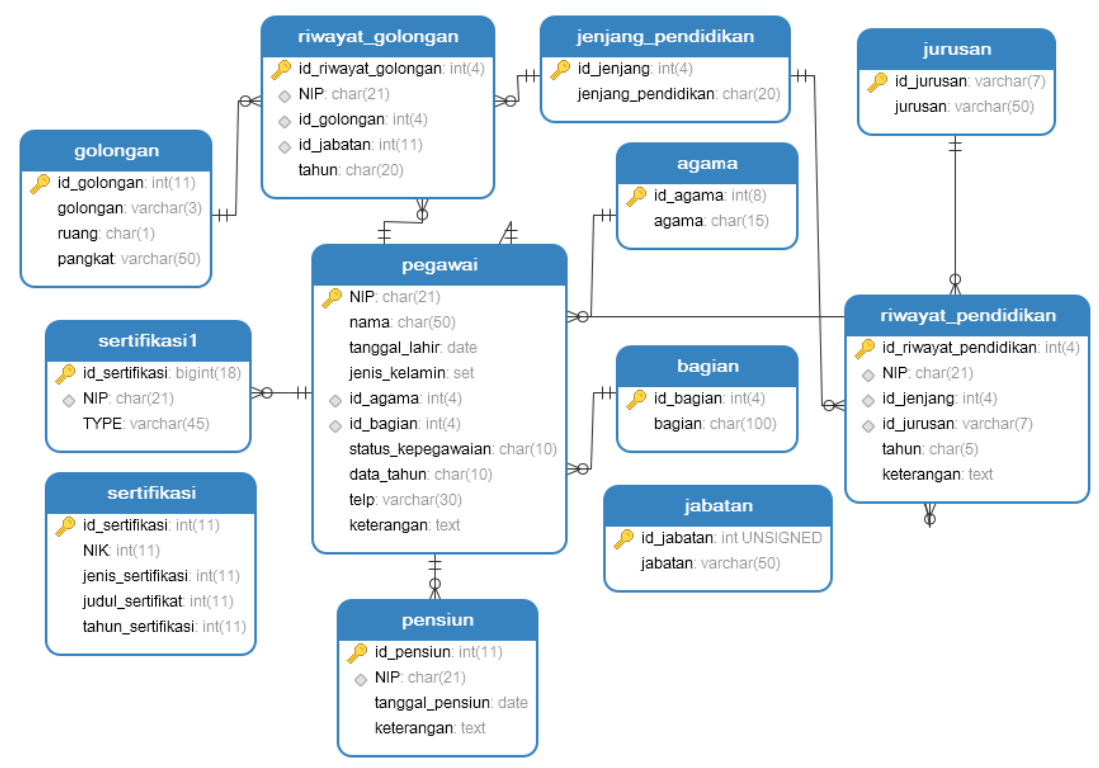

Gambar 3. Skema Database Data Kepegawaian Diterapkan 
Citec Journal, Vol. 5, No. 4, Agustus 2018 - Oktober 2018

ISSN: 2460-4259

Setelah merancang database, selanjutnya dilakukan analisa terhadap aspek-aspek kualitas database kepegawaian, yaitu analisa aspek Kebenaran, Konsistensi dan Relevansi.

\subsection{Analisa aspek Kebenaran}

Setelah semua data berhasil dipindahkan selanjutnya dilakukan pengukuran kualitas data. Pengukuran kualitas data dilakukan dengan membandingkan hasil pengujian pada database lama sebelum evaluasi dengan database baru setelah evaluasi, sedangkan untuk aspek kebenaran hanya dilakukan pada database baru setelah evaluasi. Hal ini disebabkan karena tidak adanya pembanding akurasi pada database sebelum evaluasi, sedangkan pada database baru setelah evaluasi dapat diukur tingkat akurasinya dengan menjadikan database lama sebelum evaluasi sebagai pembanding [2]. Query pengujian aspek kebenaran akan berbeda antara database lama sebelum evaluasi dengan database baru setelah evaluasi hal ini disebabkan karena adanya perubahan struktur pada database yang baru, namun perubahan query tersebut tidak akan mempengaruhi informasi yang dihasilkan. Pengukuran kualitas data aspek kebenaran dilakukan dengan mengeksekusi 35 query yang dieksekusi pada database sebelum dan setelah evaluasi, hasil pengujian kualitas data aspek kebenaran baris dan akurasi kolom ditunjukkan pada Tabel 2.

Tabel 2. Sampel Query INSERT untuk analisa aspek kebenaran

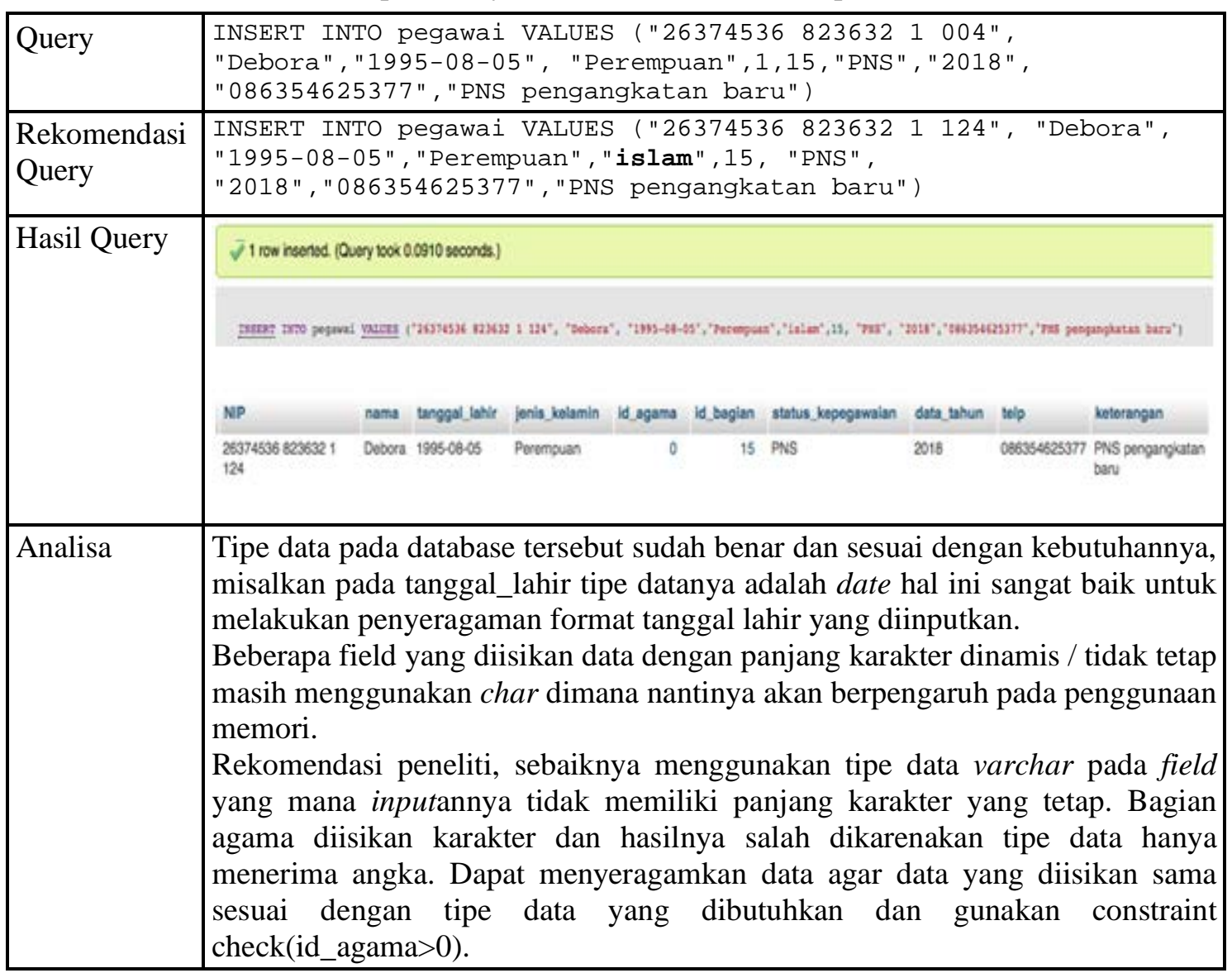

Pengukuran kualitas data aspek kebenaran dilakukan pada data pegawai yang terdapat pada tabel pegawai, jabatan, pensiun, golongan dan data pegawai yang terdapat pada tabel pensiun, yang seharusnya data pegawai dan data NIP tidak terjadi duplikasi. Untuk mengukur aspek kebenaran pada data tersebut dilakukan dengan mengeksekusi query, adapun query yang digunakan untuk pengujian kualitas data aspek kebenaran yaitu dengan mengeksekusi salah satu query contohnya INSERT. Hasil analisa kualitas data aspek kebenaran ditunjukkan pada Tabel 1. 


\subsection{Analisa aspek Konsistensi}

Pengukuran kualitas data aspek konsistensi dilakukan pada data pegawai yang terdapat pada tabel pegawai, jabatan, pensiun, golongan dan data pegawai yang terdapat pada tabel pensiun, yang seharusnya pada tabel pegawai, data nama tidak terjadi redudansi data. Untuk mengukur aspek konsistensi pada data tersebut dilakukan dengan mengeksekusi query, adapun query yang digunaka untuk pengujian kualitas data aspek konsistensi yaitu dengan mengeksekusi salah satu query contohnya JOIN. Hasil analisa kualitas data aspek kebenaran ditunjukkan pada Tabel 3.

Tabel 3. Sampel Query JOIN untuk analisa aspek Konsistensi

\begin{tabular}{|c|c|}
\hline Query & $\begin{array}{l}\text { SELECT p.NIP, p.nama, pd.id_jenjang, pd.id_jurusan, pd.tahun from } \\
\text { pegawai p LEFT join riwayat_pendidikan pd on p.NIP = pd. NIP where } \\
\text { pd.NIP ='196012111990011001' }\end{array}$ \\
\hline $\begin{array}{l}\text { Rekomenda } \\
\text {-si Query }\end{array}$ & $\begin{array}{l}\text { ADD CONSTRAINT `fk_riwayat_pendidikan` FOREIGN KEY (`NIP`) } \\
\text { REFERENCES ‘pegawai`('NIP`) ON DELETE NO ACTION ON UPDATE NO } \\
\text { ACTION }\end{array}$ \\
\hline Hasil Query & 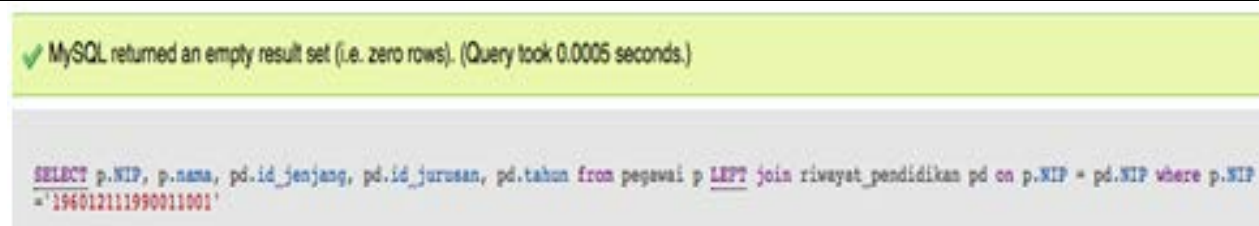 \\
\hline Analisa & $\begin{array}{l}\text { Dilakukan join tabel riwayat pendidikan dengan pegawai. hasilnya zero result. } \\
\text { Adanya perbedaan value pada NIP, seharusnya untuk tabel riwayat pendidikan } \\
\text { apabila value NIP yang diinputkan tidak terdapat pada tabel pegawai maka } \\
\text { hasilnya akan error. saat ini didapati pada tabel riwayat pendidikan tidak memiliki } \\
\text { reference pada tabel pegawai. Rekomendasi dari peniliti adalah, membutuhkan } \\
\text { referensi ke tabel pegawai dengan menggunakan query pada kolom rekomendasi } \\
\text { query di atas pada tabel } 2 \text {. }\end{array}$ \\
\hline
\end{tabular}

\subsection{Analisa aspek Relevansi}

Pengukuran kualitas data aspek relevansi dilakukan pada database pegawai dan data bagian. Untuk mengukur aspek relevansi pada data tersebut dilakukan dengan mengeksekusi query, adapun query yang digunakan untuk pengujian kualitas data aspek konsistensi yaitu dengan mengeksekusi salah satu query contohnya DELETE. Hasil analisa kualitas data aspek kebenaran ditunjukkan pada Tabel 4.

Tabel 4. Sampel Query DELETE untuk analisa aspek Relevansi

\begin{tabular}{|l|l|}
\hline Query & DELETE FROM 'pegawai'WHERE NIP='19580823 1983011001 ' \\
\hline $\begin{array}{l}\text { Rekomendasi } \\
\text { Query }\end{array}$ & ALTER TABLE 'pegawai' ADD PRIMARY KEY (NIP) \\
\hline Hasil Query & -- Indexes for table 'pegawai' \\
& $\begin{array}{l}\text { ALTER TABLE 'pegawai' } \\
\text { ADD PRIMARY KEY ('NIP'); }\end{array}$ \\
& \\
\hline
\end{tabular}




\begin{tabular}{|l|l|} 
Analisa & $\begin{array}{l}\text { Melakukan delete pada parent table namun data dalam child table tidak } \\
\text { terhapus. Data pada child table tidak terhapus sehingga apabila kita memang } \\
\text { tidak membutuhkan data pada parent table maka data pada child tabel adalah } \\
\text { sia-sia pada kasus ini. hal ini disebabkan tidak adanya referensi dari parent } \\
\text { table (pegawai) ke child table (tabel-tabel yang berelasi). Rekomendasinya, } \\
\text { dapat menggunakan action cascade delete pada tabel yang memang } \\
\text { membutuhkan, namun cascade delete tidak dapat diterapkan pada semua } \\
\text { tabel. } \\
\text { Cascade on delete akan menentukan aksi apa yang akan di lakukan terhadap } \\
\text { sebuah baris/ record dalam tabel, jika record tersebut memiliki hubungan } \\
\text { referensi (referential relationship) dan record yang di referensi di hapus } \\
\text { (DELETE) dari tabel induk (Arief, 2005) }\end{array}$
\end{tabular}

Setelah dilakukan evaluasi terhadap aspek-aspek kualitas skema database kepegawaian yang akan menjadi rujukan untuk perancangan skema database baru, kemudian dilakukan pengujian pada aspek kebenaran, konsistensi dan relevansi. Berdasarkan hasil analisis dan identifikasi key pada database kepegawaian maka dapat diketahui bahwa:

1) Masing-masing tabel pada database pegawai tersebut telah memiliki constraint primary key yang dapat menghindari inputan dengan primary key yang sama, namun beberapa data dapat diinputkan data yang sama dengan primary key yang berbeda, hal tersebut dapat menyebabkan ambigu. Misalkan dalam NIP berbeda ditemukan value yang sama di semua field. Sehingga dapat disimpulkan beberapa data yang diinputkan masih dipertanyakan kebenaran datanya dan tidak ada jaminan bahwa data yang diinputkan adalah data yang sebenarnya.

2) Ditemukan banyak terjadinya inkonsistensi data, misalkan pada NIP pengisian data tahun dan juga pengisian value yang sama di beberapa field pegawai namun dengan NIP yang berbeda. Hal tersebut mengakibatkan terjadinya redudansi data. Sehingga dapat disimpulkan skema database pegawai tersebut tidak konsisten.

3) Ditemukan ketidak relevansian pada tabel yang berelasi ketika menghapus record id pada sebuah tabel, value dari record di tabel yang berelasi tidak hilang, seharusnya hilang.

Secara keseluruhan hasil evaluasi pada database yang digunakan Kantor Kementerian XYZ saat ini sangat memungkinkan terjadinya kesalahan penambahan data (insert), kesalahan pengubahan data (update), kesalahan alam penghapusan data (delete) dan Join. Setelah dilakukan evaluasi pada database Kepegawaian Kantor Kementerian XYZ selanjutnya adalah melakukan perancangan database baru dan melakukan perbaikan perbaikan dari hasil evaluasi yang dilakukan sebelumnya, secara umum perbedaan struktur basis data sebelum dan setelah evaluasi ditunjukkan pada Tabel 5.

Tabel 5. Hasil Perbandingan Skema Database Kepegawaian

\begin{tabular}{|c|c|c|c|}
\hline \multirow{2}{*}{ Aspek } & \multirow{2}{*}{ Deskripsi } & \multicolumn{2}{|c|}{ Hasil Analisis Skema Database } \\
\hline & & Hasil Analisis & Saran dan Perbaikan \\
\hline $\begin{array}{l}\text { Kebenaran } \\
\text { (Correctness) }\end{array}$ & $\begin{array}{l}\text { Aspek yang } \\
\text { berkaitan dengan } \\
\text { penggunaan } \\
\text { hubungan antar } \\
\text { data, penggunaan } \\
\text { constraint, tipe data } \\
\text { dan hal lain } \\
\text { mengenai } \\
\text { keakuratan dalam }\end{array}$ & $\begin{array}{l}\text { Masih ada beberapa tabel } \\
\text { pada skema database } \\
\text { kepegawaian yang bersifat } \\
\text { ambigu. Sehingga belum } \\
\text { maksimal dalam memiliki } \\
\text { batasan (constraint) yang } \\
\text { dapat menghindari input } \\
\text { data yang sama. Dapat } \\
\text { disimpulkan beberapa data }\end{array}$ & $\begin{array}{l}\text { Ditambahakn beberapa } \\
\text { constraint check untuk } \\
\text { melakukan pengecekan } \\
\text { terhadap suatu value yang } \\
\text { harus dipenuhi. }\end{array}$ \\
\hline
\end{tabular}




\begin{tabular}{|c|c|c|c|}
\hline \multirow{2}{*}{ Aspek } & \multirow{2}{*}{ Deskripsi } & \multicolumn{2}{|c|}{ Hasil Analisis Skema Database } \\
\hline & & Hasil Analisis & Saran dan Perbaikan \\
\hline & $\begin{array}{l}\text { masukan dan } \\
\text { penyimpanan data. } \\
\text { Contohnya } \\
\text { pemilihan data yang } \\
\text { harus sesuai } \\
\text { kondisi. }\end{array}$ & $\begin{array}{l}\text { tidak ada jaminan } \\
\text { kebenarannya. }\end{array}$ & \\
\hline $\begin{array}{l}\text { Konsistensi } \\
\text { (Consistency) }\end{array}$ & $\begin{array}{l}\text { Aspek ini agar tidak } \\
\text { redudansi data } \\
\text { dalam semua aspek } \\
\text { dalam setiap tabel } \\
\text { database yang } \\
\text { terelasi. Aspek } \\
\text { yang menjadi tolak } \\
\text { ukur dalam } \\
\text { penerimaanya ke } \\
\text { pengguna. } \\
\text { Konsisten tersebut } \\
\text { untuk mengatasi } \\
\text { duplikasi data. }\end{array}$ & $\begin{array}{l}\text { Masih ditemukan } \\
\text { banyaknya inkonsistensi } \\
\text { data pada beberapa tabel } \\
\text { data kepegawaian. Hal } \\
\text { tersebut tentunya } \\
\text { mengakibatkan terjadinya } \\
\text { redudansi data. Maka } \\
\text { disimpulkan skema } \\
\text { database kepegawaian } \\
\text { tersebut tidak konsisten. }\end{array}$ & $\begin{array}{l}\text { Menambahkan action pada } \\
\text { primary key (cascade } \\
\text { delete dan atau cascade } \\
\text { update) sehingga apabila } \\
\text { terjadi perubahan atau } \\
\text { penghapusan data pada } \\
\text { parent table diubah maka } \\
\text { nantinya akan berdampak } \\
\text { pula ke child tabel sesuai } \\
\text { dengan action yang } \\
\text { diberikan. } \\
\text { Kemudian menambahkan } \\
\text { constraint unique agar } \\
\text { tidak terjadinya data } \\
\text { dengan NIK yang berbeda } \\
\text { namun setiap field datanya } \\
\text { sama. }\end{array}$ \\
\hline $\begin{array}{l}\text { Relevansi } \\
\text { (Relevance) }\end{array}$ & $\begin{array}{l}\text { Mengukur dengan } \\
\text { aspek teknik } \\
\text { database yang } \\
\text { relevan dalam } \\
\text { penggunaanya. Hal } \\
\text { yang berkaitan } \\
\text { dengan hubungan } \\
\text { antar tabel database } \\
\text { apakah relevan , } \\
\text { contohnya } \\
\text { hubungan relevansi } \\
\text { antar primary key } \\
\text { dengan anak } \\
\text { induknya. }\end{array}$ & $\begin{array}{l}\text { Masih memuat banyak } \\
\text { skema yang tidak ada } \\
\text { relevansinya dengan skema } \\
\text { lainnya. Maka disimpulkan } \\
\text { skema database } \\
\text { kepegawaian belum } \\
\text { relevansi. }\end{array}$ & $\begin{array}{l}\text { Dilakukan reference } \\
\text { primary key pada parent } \\
\text { table ke foreign key di } \\
\text { child table. }\end{array}$ \\
\hline
\end{tabular}

Berdasarkan evaluasi tersebut, maka dibentuklah skema database yang baru sesuai rekomendasi dalam beberapa aspek, ditunjukan pada Gambar 4. Terdapat beberapa tabel tambahan yang lebih rinci dan penggunaan tipe data maupun lebar data untuk memenuhi aspekaspek skema dalam database yaitu aspek kebenaran, konsistensi dan relevansi. 
Citec Journal, Vol. 5, No. 4, Agustus 2018 - Oktober 2018

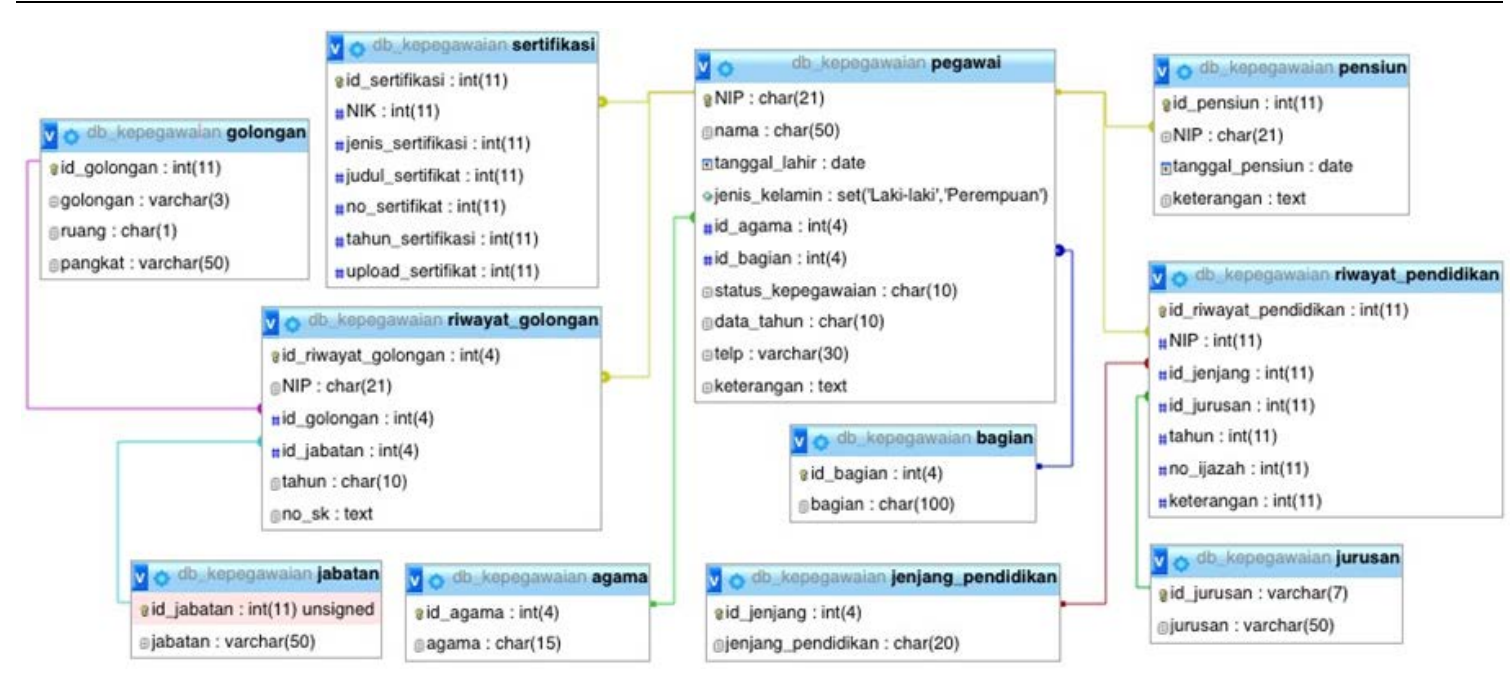

Gambar 4. Rekomendasi Skema Database Kepegawaian

Penghapusan pada tabel v pegawai dan view pegawai yang tidak diperlukan karena sudah terdapat tabel pegawai, serta tabel sertifikasi 1 karena terdapat 2 tabel yang sama. Hal tersebut salah satunya menimbulkan inkonsistensi pada skema sehingga data mengalami redudansi yang akan berpengaruh pada nilai kebenaran pada database tersebut.

\section{KESIMPULAN}

Penelitian ini melakukan analisis terhadap aspek-aspek kualitas pada skema database. Analisis database dilakukan pada Kantor Kementerian XYZ. Berdasarkan hasil analisa dengan perancangan database yang ada, maka dapat diambil kesimpulan yaitu:

1. Pada analisa aspek kebeneraan yaitu masih ada beberapa tabel pada skema database kepegawaian yang masih ambigu, yaitu belum memiliki constraint yang jelas sehingga terjadi input data yang sama.

2. Terjadinya inkonsistensi yaitu pada action primary key, jika terjadi cascade delete pada parent table dan hal tersebut berpengaruh pada penghapusan child parent.

3. Hasil pada analisa relevansi masih diperlukan reference primary key pada parent table ke foreign key di child table.

\section{SARAN}

Adapun saran untuk penelitian lebih lanjut adalah penelitian ini masih berupa rancangan database terhadap sistem kepegawaian kementerian XYZ secara online, sehingga yang masih diperlukan adalah tahapan yang dilakukan selanjutnya. Selain bentuk skema database baru sesuai aspek yang disesuaikan kebutuhan dan batasan sistem, saran lain adalah adanya implementasi terhadap sistem yang baru yang terintegrasikan dengan sistem lain untuk meningkatkan daya kebergunaannya. Kemudian peneliti rangkum sebagai berikut:

1. Kementerian secara berkala dalam merekrut pegawai untuk menyesuaikan kembali seluruh kebutuhan SDM akan berhasil jika perencanaan SDM sudah sangat matang, salah satunya dengan mengetahui kebutuhan SDM melalui database kepegawaian dengan menganalisis tabel pegawai dengan tabel jabatan dan tabel pensiun.

2. Rekomendasi perancangan database yang sesuai dengan kebutuhan kementerian XYZ dalam menghasilkan tabel-tabel atau skema database baru agar dikembangkan ke tahapan implementasi. 
3. Database pada kepegawaian kementerian XYZ relatif masih perlu banyak perbaikan yang bisa menimbulkan potensi timbulnya masalah di kemudian hari. Perlu dilakukan penyempurnaan berdasarkan skema database rekomendasi, sehingga masalah yang ditimbulkan pada sistem yang berjalan bisa teratasi untuk menghindari permasalahan yang lebih kompleks

\section{DAFTAR PUSTAKA}

[1] Gat, 2015, Perancangan Basis Data dengan Menerapkan Model Data Relasional, Citec Journal, No, 4, Vol. 2, Hal. 304-315.

[2] Raharjo, S., Sutant, E., Utami, E., 2007, Analisis Aspek-aspek Kualitas Schema Database, Seminar Nasional Teknologi 2007, Yogyakarta, November 24

[3] Whitten, J. L., Bentley, L. D., Dittman, K. C., 2004, System Analysis and Design Methods, (6th ed). McGraw-Hill, Pennsylvania

[4] Azizah, N., Mulyandi, R., Monica, 2013, Rancang Bangun Sistem Informasi Penggajian Guru Berbasis Web Pada SMA Negeri 6 Tangerang, Jurnal Eksplora Informatika, No. 2, Vol.2, Hal. 147-158

[5] Al fatta, H., 2007, Analisis \& Perancangan Sistem Informasi, Andi Publisher, Yogyakarta.

[6] McLeod, R. Jr., Schell, G., 2001, Management Information Systems, Pearson Prentice-Hall, London.

[7] Arief, M. R., 2005, Pemrograman Basis Data dengan Transact-SQL menggunakan SQL Server, Andi Publisher, Yogyakarta.

[8] Utami, E., Hartanto. A. D., 2012, Sistem Basis Data Menggunakan Microsoft SQL Server 2005, Andi Publisher, Yogyakarta. 